\title{
Efforts to Find Targets Involving Angiogenesis: Step to Improve the Efficacy of Target Therapy in the Era of Colorectal Cancer Treatment
}

\author{
In Ja Park \\ Department of Colon and Rectal Surgery, Asan Medical Center, University of Ulsan College of Medicine, Seoul, Korea
}

See Article on Page 9-15

Continuous efforts have been made to find an effective treatment to improve oncologic outcomes for patients with colorectal cancer. These efforts have accomplished a noticeable achievement by using biomarker-based approaches. Antiangiogenic drugs that target the vascular endothelial growth factor (VEGF) signaling pathway have successfully expanded clinical treatment options for many cancer types, including colorectal cancer in the advanced metastatic disease setting. Although VEGF inhibitors have led to progress in the treatment of patients with metastatic colorectal cancer, the development of resistance to VEGF inhibitors has emerged as a problem to be solved. Thus, we need to discover ways to enhance the efficacy of VEGF inhibitors and to evaluate other potential targets involved in angiogenesis.

Together with the VEGF, angiopoietin-1 (Ang-1), angiopoietin-2 (Ang-2), and their receptor Tie-2 make up another system that is involved in the regulation of angiogenesis [1,2]. Ang-2 is a pro-angiogenic, pro-inflammatory cytokine that is involved in vascular growth and maturation. Ang-1/Tie-2 signaling confers structural stability to mature vessels and protects the endothelium from activation by exogenous cytokines, including angiogenetic and inflammatory stimuli [3]. In many malignances, the angiopoietin-Tie pathway is known to be involved in carcinogenesis and metastasis [4].

The authors of "Expressions and Clinical Significances of An-

Correspondence to: In Ja Park, M.D.

Department of Colon and Rectal Surgery, Asan Medical Center, University of Ulsan College of Medicine, 88 Olympic-ro 43-gil, Songpa-gu, Seoul 05505, Korea

Tel: +82-2-3010-3937, Fax: +82-2-474-9027

E-mail: ipark@amc.seoul.kr

(C) 2017 The Korean Society of Coloproctology

This is an open-access article distributed under the terms of the Creative Commons Attribution NonCommercial License (http://creativecommons.org/licenses/by-nc/4.0) which permits unrestricted noncommercial use, distribution, and reproduction in any medium, provided the original work is properly cited. giopoietin-1, Angiopoietin-2, and Tie-2 Receptor in Patients With Colorectal Cancer" used immunohistochemistry (IHC) to study the expressions of Ang-1, Ang-2, and Tie-2 in colorectal cancer tissue [5]. They found that Ang-1, Ang-2, and Tie-2 were overexpressed in colorectal cancer tissues. They also found that overexpression of Ang-2 had a significant relationship with lymph node metastasis and that high overexpression of Ang-2 had a significant relationship with poor clinical outcome. Although assessments of the associations of Ang-1, Ang-2, and Tie-2 expressions based on IHC with clinical features and outcomes need to be a fundamental step in treatment target development, such assessments are potentially limited as target evaluations because they do not provide a quantified objective value and may be influenced by observer variance. Thus, functional assessments of the associations between the expressions of Ang-1, Ang-2, and Tie-2 and the clinical features and outcomes for patients with colorectal cancer need to be evaluated further.

Recently, a study reported a significant association between the concentration of Tie- 1 , which interacts with Tie-2, and the overall survival benefit of regorafenib [6]. Associations between treatment efficacy and the expressions of angiogenesis-related factors must be continuously analyzed in further studies, the results of which should improve the efficacy of angiogenesis target treatment.

\section{CONFLICT OF INTEREST}

No potential conflict of interest relevant to this article was reported.

\section{REFERENCES}

1. Saharinen P, Eklund L, Pulkki K, Bono P, Alitalo K. VEGF and angiopoietin signaling in tumor angiogenesis and metastasis. Trends Mol Med 2011;17:347-62.

2. Albini A, Noonan DM. Angiopoietin2 and tie2: tied to lymphangiogenesis and lung metastasis. New perspectives in antimetastat- 
ic antiangiogenic therapy. J Natl Cancer Inst 2012;104:429-31.

3. Aoi J, Endo M, Kadomatsu T, Miyata K, Nakano M, Horiguchi H, et al. Angiopoietin-like protein 2 is an important facilitator of inflammatory carcinogenesis and metastasis. Cancer Res 2011;71: 7502-12.

4. Huang H, Bhat A, Woodnutt G, Lappe R. Targeting the ANGPTTIE2 pathway in malignancy. Nat Rev Cancer 2010;10:575-85.

5. Hong S, Jung HI, Ahn TS, Kim HJ, Lee KT, Baek MJ, Bae SB. Ex- pressions and clinical significances of angiopoietin-1, angiopoietin-2, and Tie-2 receptor in patients with colorectal cancer. Ann Coloproctol 2017;33:9-15.

6. Tabernero J, Lenz HJ, Siena S, Sobrero A, Falcone A, Ychou M, et al. Analysis of circulating DNA and protein biomarkers to predict the clinical activity of regorafenib and assess prognosis in patients with metastatic colorectal cancer: a retrospective, exploratory analysis of the CORRECT trial. Lancet Oncol 2015;16:937-48. 